\title{
Cement-Polymer Composites for Oilwell Cementing
}

\author{
A. Chougnet ${ }^{1,3^{*}}$, A. Audibert-Hayet ${ }^{1 * *}$, M. Moan ${ }^{2}$, E. Lécolier ${ }^{1}$ and B. Guichard ${ }^{3}$ \\ 1 Institut français du pétrole, IFP, Direction Chimie et Physico-Chimie Appliquées, 1-4 avenue de Bois-Préau, \\ 92852 Rueil-Malmaison Cedex - France \\ 2 Laboratoire de Rhéologie, Université de Bretagne Occidentale, 6 avenue Le Gorgeu, 29285 Brest Cedex - France \\ 3 Eliokem, 14 avenue des tropiques, 91955 Courtaboeuf Cedex - France \\ e-mail: achougnet@clamart.oilfield.slb.com - annie.audibert-hayet@total.com - michel.moan@univ-brest.fr \\ eric.lecolier@ifp.fr - bertrand-guichard@eliokem.com \\ * Present address: Schlumberber Oilfield Services, 1 rue Becquerel, 92140 Clamart - France \\ ** Present address: TOTAL, 2 place Jean Millier, 92078 Paris La Défense - France
}

\begin{abstract}
Résumé - Composites ciment-polymère pour la cimentation des puits pétroliers - La durabilité des matériaux utilisés pour les sondages pétroliers est une question essentielle pour garantir l'étanchéité à long terme des puits. Des composites ciment/polymère présentent de bonnes propriétés mécaniques et de durabilité : il est en effet connu que l'ajout de latex améliore l'adhésion ou la flexibilité des pâtes de ciment durcies. Ainsi, des composites ciment/polymère apparaissent comme de bons matériaux de cimentation de puits dans des environnements sévères. Lors de la construction d'un puits, le placement du laitier de ciment dépend très fortement de ses propriétés rhéologiques. Dans cet article, nous avons étudié les propriétés rhéologiques de suspensions composites à base de ciment et de poudre de polymère : nous montrons que sous cisaillement oscillatoire, ces suspensions présentent une transition d'un état gélifié vers un état de type liquide. Le remplacement d'une partie des particules de ciment par des particules de polymère induit une baisse du module de conservation de l'état gel. La bonne dispersion des particules de polymères et leur forte affinité pour les grains de ciment ont été observées par microscopie électronique. Des expériences de spectroscopie RMN et de calorimétrie ont mis en évidence une influence de l'addition de particules de polymères sur les mécanismes d'hydratation et de durcissement de la matrice cimentaire. L'ensemble des résultats acquis a amélioré notre compréhension des relations entre la composition du coulis, son comportement rhéologique et les propriétés du matériau durci, ce qui nous a permit de formuler de nouveaux matériaux de cimentation.
\end{abstract}

\begin{abstract}
Cement-Polymer Composites for Oilwell Cementing - The selection of an optimal cementitious material is critical to maintain zonal isolation for the lifetime of oil \& gas or gas storage wells not only for primary cementing but also after well abandonment. Polymer powder/cement composites present good mechanical and durability properties since polymer latex promotes improved adhesion and flexibility to the hardened cement paste. So, for well constructions in aggressive environment, polymer powder/cement composites would be good candidates. During the well construction, the cement slurry placement strongly depends on its rheological behaviour. In this paper, we studied rheological properties of polymer powder/cement composite suspensions: they present a transition from a gel to a liquid behaviour in oscillatory shear. The replacement of cement particles by polymer particles induces a decrease of the storage modulus in the gel state. The good quality of the polymer particle dispersion and their high affinity for cement particles were observed by Scanning Electron Microscopy (SEM). Solid state NMR $\left({ }^{29} \mathrm{Si}\right.$ and $\left.{ }^{27} \mathrm{Al}\right)$ and calorimetry allowed to highlight the influence of the polymer addition on both the hydration and hardening of the cement matrix. All these results helped us to understand the relations between the slurry composition, its rheological behaviour and the properties of the hardened materials which allowed us to design new cementing materials.
\end{abstract}




\section{INTRODUCTION}

Cementitious materials used for oil and gas well construction have to permanently isolate the subsurface formations penetrated by the well or to durably fill up the wells when they are abandoned. Therefore they have to exhibit a large range of properties such as good mechanical and durability properties. Polymer powder/cement composites are known to have higher tensile strength, deformability, adhesion, waterproofness and durability than conventional cementbased materials [1]. For this reason, polymer-modified cements are used in the construction industry as, for example, repairing materials, anticorrosive coatings or tile adhesives. Besides, adding suitable polymer particles is a way to lighten slurries without impairing mechanical and durability properties [2]. All these reasons make polymer powder/cement composites interesting materials for oilwell cementing.

One can find many studies on the mechanical or durability properties of those composite materials in the literature [3-11]. Surprisingly, only a few authors [12-14] have studied the rheology of the cement-polymer composite pastes. However, such studies are necessary for oilwell applications since the slurries are pumped down in the wells over great distances. In the first part of this work, we propose to characterize in details the behavior of the suspensions both with oscillatory shear experiments and to compare the rheological parameters obtained. In addition, the use of a controlled stress rheometer permits to have a better insight into the gel-liquid transition. The influence of the solid volume fraction on the different parameters will also be studied.

Moreover, for well cementing operations, the setting time has to be very well-known and controlled. Some authors showed that adding latex or redispersible powder delays the hydration reactions [14-16]. We therefore performed calorimetry measurements on the composite pastes.

Besides, it has been described that adding polymer modifies the mineral assemblage of the cementitious matrix: the presence of polymer seems to reduce the amounts of both portlandite [16-17] and ettringite [18]. In this study, we characterized the calcium silicate hydrates (noted C-S-H) by ${ }^{29} \mathrm{Si} \mathrm{NMR}$ and the aluminate hydrates by ${ }^{27} \mathrm{Al}$ NMR to assess the hydration processes in cement-polymer composites.

Finally, as an example of application of the previous studies, incorporation of polymer powder in a low permeability cement system adapted to well construction has been investigated.

\section{BACKGROUND}

\subsection{Oilwell Cementing [19]}

Rotary drilling is the worldwide method used to drill oil and gas wells. This method consists in the use of a rotating bit which crushes the rock formation, and a continuous drilling fluid injection, which removes the rock cuttings and brings them to the surface. One of the main advantages of the rotary method is that the drilling fluid can be pumped through the bit. Once a section of the well has been drilled, the drill pipe is removed from the hole and a casing pipe is run into the hole until it reaches the bottom. This operation is achieved with the borehole full of drilling fluid. Once the casing pipe is in place, a cement slurry is pumped down into the casing string to the bottom of the well and then flows up through the annulus between the casing and the borehole wall (Fig. 1). This last operation is called primary cementing.

The major goal of the primary cementing is to provide a complete and permanent zonal isolation within the well bore. This means that the cement sheath must prevent any fluid circulation (gas, oil, water, etc) between different rocks layers.

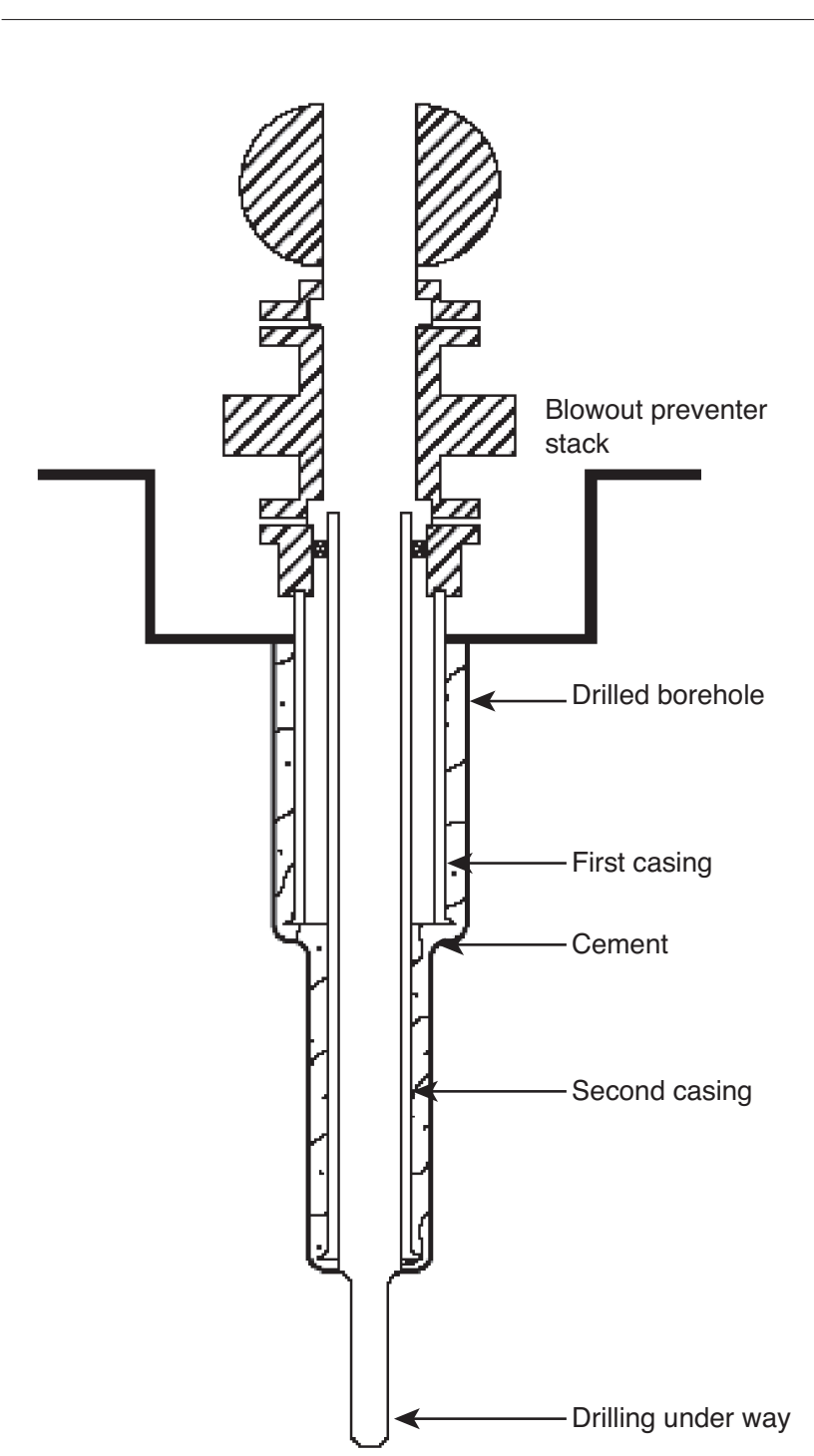

Figure 1

Simplified cross-section of a borehole. 
To achieve this objective, the drilling fluid must be removed from the annulus and the cement slurry put in place. Therefore, good mud removal and cement placement are essential to avoid interzonal fluid flows. The drilling fluids removal is strongly dependent of the fluids rheological properties [19]. Incomplete zonal isolation may lead to environment pollution problems or production rates lower than expected. That is why primary cementing is often considered as one of the most important operations performed in a well. Primary cementing also aims at mechanically securing the casing string to the borehole walls and at protecting the casing from corrosion by the fluids contained in the drilled rock formations. To avoid mechanical failure of the cement sheath, the cementing material has to be carefully designed and adapted to the specific conditions encountered downhole: the mechanical properties (such as Young's modulus) must be optimized with respect to mechanical loading.

Primary cementing is not the only cementing operation. After more than 20 years, when the production rate becomes very low, the wells have to be plugged. The main aim of well abandonment is to permanently seal the well bore for a geological time scale in order to prevent any leakage of formation fluids to surface.

Consequently, long-term durability of the materials used for primary cementing and for plugging is of paramount importance. Innovative solutions, such as organic-inorganic composites, for the wells construction are required for the future.

\subsection{Cement Hydration [19, 20]}

The mineral mixture used in cementing operations is either a pure cement paste or a fine mortar, i.e. a mixture of cement and fine mineral particles like silica fume, with organic admixtures. Cement itself is a mixture of several mineral phases, the most abundant being an impure tricalcium silicate, $3 \mathrm{CaO} \mathrm{SiO}_{2}$ (alite) and its dicalcium equivalent, $2 \mathrm{CaO} . \mathrm{SiO}_{2}$ (belite). Oil well cements are particularly rich in silicate phases. According to American Petroleum Institute standards, tricalcium aluminate content of a class $\mathrm{G}$ cement must be lower than $3 \%$. When cement is mixed with water, it undergoes a dissolution reaction generating, among others, calcium, silicate and aluminate ions in the interstitial solution. After a few hours, new products called "hydrates" precipitate, the most important being calcium silicate hydrate (C-S-H) and calcium hydroxyde (portlandite). This dissolution-diffusion-precipitation process yields a geometrically complex interface between the anhydrous silicate and C-S-H on one hand and between the hydrates and the solution on the other hand. As the hydration reaction proceeds, more and more anhydrous material is converted into hydrates, with an overall decrease of the porosity since the volume of hydrates produced by the thorough reaction of tricalcium silicate with water is more than twice the initial anhydrous volume [21].
Two important mechanical events occur during hydration [22]. The first one is a simple gelation of the slurry, due to the high ionic strength of the aqueous phase [23-25]. It occurs quasi-immediately after mixing the cement with water, at virtually zero hydration. The coagulated network has a poor mechanical strength. The second and more important event is setting, which starts a few hours after coagulation. The period between coagulation and setting is (improperly) called the dormant period. In fact, hydrate particles nucleation is occurring, followed by their growth [26]. A continuous reinforcement process is going on in contact areas, leading, at some point, to mechanical percolation (setting). At this point, the shear modulus is in the GPa range. Further hydration and (misunderstood) long term redistribution of matter and voids [27] leads to further reinforcement, over periods of weeks, months or even years. The final microstructure developed during this process is an important key for the long term integrity of the cementing material. Indeed, both chemical reactions and transport of chemical species (water, gas molecules, ionic species) within the cement paste is driven by the texture and the topology of the porous cementitious matrix. Hardened cement paste is a good example of Mesoscopic Divided Material (MDM) for which an internal surface partitions and fills the space in a very complex way [28, 29].

A crucial question from both fundamental and industrial standpoints is to know how polymer powder addition modifies hydration and macroscopic properties (i.e. mechanical strength and transport properties).

\subsection{Rheological Properties of Cementitious Slurries}

As Shaughnessy and Clark [30] mention in their review, many studies of the rheological properties of fresh cement pastes can be found in the literature. Under shear, cement suspensions without additives are thixotropic fluids presenting an apparent yield stress and a shear thinning behaviour. These characteristics are generally interpreted by the existence of globally attractive forces between cement particles that are responsible for the aggregation of the particles, the yield stress being linked to the gelation of the suspension, and the shear thinning behaviour being explained by the progressive crumbling under shear rates. At high shear rate and for concentrated cement pastes, some authors also observed shear-thickening, which could be due to the increase of the aggregate size under shear $[30,31]$. At rest, the aggregates tend to form a single continuous large aggregated phase and the suspension gels. This gel state was studied in oscillatory shear [22, 32] with controlled strain rheometers. Nachbaur et al. [22] characterised the behaviour of the suspensions by varying the strain amplitude or the frequency: they showed that in the linear viscoelastic domain, the suspension has a solidlike behaviour. They linked the very small values of the 
critical strains to the physical and short-range nature of the attractive inter-particle forces.

\section{MATERIALS AND METHODS}

Cement. In this study, we used portland cement, an API class $\mathrm{G}$ one produced by Dyckerhoff which is considered as a representative oilwell cement. Its chemical analysis and mineralogical composition are given in Tables 1 and 2 respectively.

TABLE 1

Chemical analysis of API Class G cement

\begin{tabular}{c|c}
\hline Oxide & $\operatorname{wt}(\%)$ \\
\hline $\mathrm{CaO}$ & 64.70 \\
\hline $\mathrm{SiO}_{2}$ & 22.91 \\
\hline $\mathrm{Al}_{2} \mathrm{O}_{3}$ & 3.89 \\
\hline $\mathrm{Fe}_{2} \mathrm{O}_{3}$ & 4.75 \\
\hline $\mathrm{SO}_{3}$ & 1.80 \\
\hline $\mathrm{MgO} \mathrm{Na}$ & 0.74 \\
\hline $\mathrm{Na}_{2} \mathrm{O}$ & 0.10 \\
\hline $\mathrm{K}_{2} \mathrm{O}$ & 0.64 \\
\hline
\end{tabular}

TABLE 2

Bogue composition of API Class G cement

\begin{tabular}{c|c}
\hline Mineral & $\operatorname{wt}(\%)$ \\
\hline $\mathrm{C}_{3} \mathrm{~S}$ & 51.2 \\
\hline $\mathrm{C}_{2} \mathrm{~S}$ & 27.0 \\
\hline $\mathrm{C}_{3} \mathrm{~A}$ & 2.3 \\
\hline $\mathrm{C}_{4} \mathrm{AFx}$ & 14.5 \\
\hline
\end{tabular}

Redispersible polymer powder. The redispersible powder was used as received from Eliokem. The powder was obtained by drying a polystyrene acrylate latex. The polymer particles are very polydisperse in size, with a number average diameter of $0.5 \mu \mathrm{m}$ and a volume average diameter of $150 \mu \mathrm{m}[33]$.

Polymer/cement composite suspensions. The polymer and cement powders were first mixed in a three-dimensional mixer for 10 minutes. The powders were then added to deionised water in a blender, with the same mixing protocol as for cement slurries.

The composite suspensions are characterised by the ratio: $\varphi_{c w}=\frac{V_{c}}{V_{w}+V_{c}}$ with $V_{w}$ and $V_{c}$ the respective volumes of water and cement. For the suspensions studied, $\varphi_{c w}$ ranged between 0.39 and 0.47 . For a given value of $\varphi_{c w}$, different amounts of polymer powder were added; when it was possible, we added a volume of polymer up to a fraction of 0.79 of the cement (in weight, it corresponds to a ratio of 0.25 ). The total solid volume fractions of composite suspensions were comprised between 0.42 and 0.54 .

Rheological measurements. Most of the rheological measurements were made using a stress controlled Haake RS150 rheometer at $20^{\circ} \mathrm{C}$. To avoid slipping at the walls, a four blades vane geometry and a grooved stator were used [34]. The suspensions were first pre-sheared at $1000 \mathrm{~s}^{-1}$ for a few minutes and then left at rest until no more settling was observed (about 30 minutes for a typical cement suspension). For oscillatory shear experiments, increasing shear stress amplitudes at a given frequency of $1 \mathrm{~Hz}$, or increasing frequencies at a given shear stress amplitude were applied. Complementary experiments in oscillatory mode were performed with a strain controlled Ares rheometer, at $20^{\circ} \mathrm{C}$ : after a pre-shearing at $200 \mathrm{~s}^{-1}$ of a few minutes and a rest period of $30 \mathrm{~min}$ for cementitious suspensions, increasing deformation amplitudes at a given frequency of $1 \mathrm{~Hz}$ were applied.

Solid state nuclear magnetic resonance. For ${ }^{29} \mathrm{Si}$ and ${ }^{27} \mathrm{Al}$ solid state NMR measurements, a Bruker ASX500 spectrometer (11.7 T) was used. Single-pulse experiments were carried out, with $\pi / 2$ pulses for ${ }^{29} \mathrm{Si}$ spectra and $\pi / 12$ pulses for ${ }^{27} \mathrm{Al}$ spectra. Hardened cement pastes were ground and the powder were placed into $\mathrm{ZrO}_{2}$ rotors of $7 \mathrm{~mm}$ length for ${ }^{29} \mathrm{Si}$ spectra and $4 \mathrm{~mm}$ length for ${ }^{27} \mathrm{Al}$ spectra. The spinning rate of the $7 \mathrm{~mm}$ rotors was $5 \mathrm{kHz}$ and the one of the $4 \mathrm{~mm}$ rotors was $14 \mathrm{kHz}$.

Calorimetry. Calorimetry measurements were made using a Setaram C80 calorimeter. After mixing, cement pastes were poured into Pyrex vessels that were introduced in the calorimeter vessels. Isothermal steps were applied, with a pressure of $9 \mathrm{MPa}$ of nitrogen. The heat flow was measured during $48 \mathrm{~h}$, and extrapolated until 5 days of hydration. After that period of hydration, the heat flows become too low to be measured with this method.

Compressive strength measurement. Unconfined compressive strength corresponds to the maximum stress the specimens can withstand. The unconfined compressive strength has been measured with a loading rate of $5.8 \mathrm{kN} / \mathrm{min}$ until failure on cylinders with dimensions of $25 \mathrm{~mm}$ diameter and $50 \mathrm{~mm}$ height. We note, $R_{c}$, the compressive strength. For each set of measurements, a minimum of 5 cylinders were tested. The average of the measurements is given in this paper.

Water permeability. As mentioned earlier, the main aim of the cementing operations (primary cementing and plugging) is to avoid fluid circulation between different geological layers. In absence of large cracks in cement sheath (and plug) or micro-annuli at the interfaces cement/rock or cement/casing, the transport of fluids within the cementitious matrix is mainly a diffusive process. To characterize the evolution of 
the transport properties of the matrix, the diffusion coefficient of ionic species should be measured instead of the permeability. Nonetheless, permeability of a cement-based material is assumed to be a relevant index to assess its durability. In this work, water permeability has been measured by using an home-made Hassler type cell. The experiment consists in applying a differential pressure between the opposite sides of a cylinder in order to develop a water flow, and in recording the corresponding flow rate. The flow rate is determined by continuously weighing the water at the outlet of the setup. To force the water through the cementitious matrix and to prevent water leakage, the set cementitious sample is placed in a deformable sleeve which is pressurized to ensure water tightness. The upward pressure, $P_{1}$, is fixed at the confining pressure minus $3 \mathrm{MPa}$. The downward pressure, $P_{2}$, is equal to atmospheric pressure. Darcy's law for a non-compressible fluid is used to calculate the water permeability $k_{w}$ :

$$
Q=k_{w} \frac{S}{\eta} \frac{P_{1}-P_{2}}{l}
$$

where $\eta(\mathrm{Pa} \cdot \mathrm{s})$ is the water viscosity at the measurement temperature, $l(\mathrm{~m})$ and $S\left(\mathrm{~m}^{2}\right)$ are respectively the length and the cross-sectional area of the tested cylinder and $Q$ the flow rate $\left(\mathrm{m}^{3} \cdot \mathrm{s}^{-1}\right)$.

\section{RESULTS AND DISCUSSION}

\subsection{Rheological Properties}

\subsubsection{Cement Suspensions}

Figure 2 shows the variation of both the storage modulus, $G^{\prime}$, and the viscous modulus, $G^{\prime \prime}$, with the amplitude $\tau^{0}$ of the applied shear stress, at a given frequency of $1 \mathrm{~Hz}$. As shown by Chougnet et al. [35], this behaviour is identical to silica suspensions one. One can consider silica suspensions as chemically inert over rheological measurement timescale. Thus, the cement behaviour shown in Figure 2 cannot be attributed to the chemical evolution of the cement paste, which is studied in the present work during the so-called dormant period. The two curves $G^{\prime}\left(\tau^{0}\right)$ and $G^{\prime \prime}\left(\tau^{0}\right)$ are characterised by a sharp fall-off from a high-modulus plateau at low shear stress to a relatively gradual leveling-off towards a low-modulus asymptote at high shear-stress. The sharp drop of typically four to five decades is observed at a critical stress $\tau_{c}^{0}$. This critical stress value corresponds to an important change of the material structure over a very narrow range of increasing shear stresses. This is also consistent with the fact that at low stress $\left(\tau^{0}<\tau_{c}^{0}\right), G^{\prime}>G^{\prime}$, while the opposite, $G^{\prime}<G^{\prime}$, is observed at high shear stresses $\left(\tau^{0}>\tau_{c}^{0}\right)$. This kind of behaviour has already been observed for concentrated monodisperse silica suspensions [31], and for monodisperse polymethylmethacrylate spheres dispersed in polydimethylsiloxane [36]. For our cement slurries, the critical stress $\tau_{c}^{0}$ increases with solid volume fraction (see Tab. 3).

TABLE 3

For cement slurries of different solid volume fractions, $\varphi$ values of storage modulus in the gel state, $G_{\text {gel }}$, critical stress amplitude, $\tau_{c}^{0}(\mathrm{~Pa})$ and complex viscosity in the liquid state $\eta_{1}{ }^{*}$.

\begin{tabular}{c|c|c|c}
\hline$\varphi$ & $G_{\text {gel }}^{\prime}\left(\times 10^{3} \mathrm{~Pa}\right)$ & $\tau_{c}^{0}(\mathrm{~Pa})$ & $\eta_{1}{ }^{*}(\mathrm{~Pa} \cdot \mathrm{s})$ \\
\hline 0.39 & 25 & 20 & 0.07 \\
\hline 0.44 & 38 & 50 & 0.14 \\
\hline 0.47 & 50 & 75 & 0.24 \\
\hline 0.49 & 75 & 100 & 0.35 \\
\hline
\end{tabular}

The data of Figure 2 have been replotted versus the strain amplitude in Figure 3. Plateaus at low and high strains are observed. But the previous sharp drop is replaced by a gradual fall-off over a large range of increasing strains. A critical deformation amplitude $\gamma_{c}^{0}$ can be defined when the elastic modulus reaches $95 \%$ of $G_{\text {gel }}^{\prime}$. Contrary to the critical stress defined above, the critical deformation does not depend on the volume fraction. The low value of $\gamma_{c}^{0} \sim 0.15 \%$ suggest that the gel formed is a physical gel rather than a chemical gel implying stronger bindings between particles [22, 37].

The presence of the two plateaus can be interpreted in terms of two linear or quasi-linear viscoelastic regions,

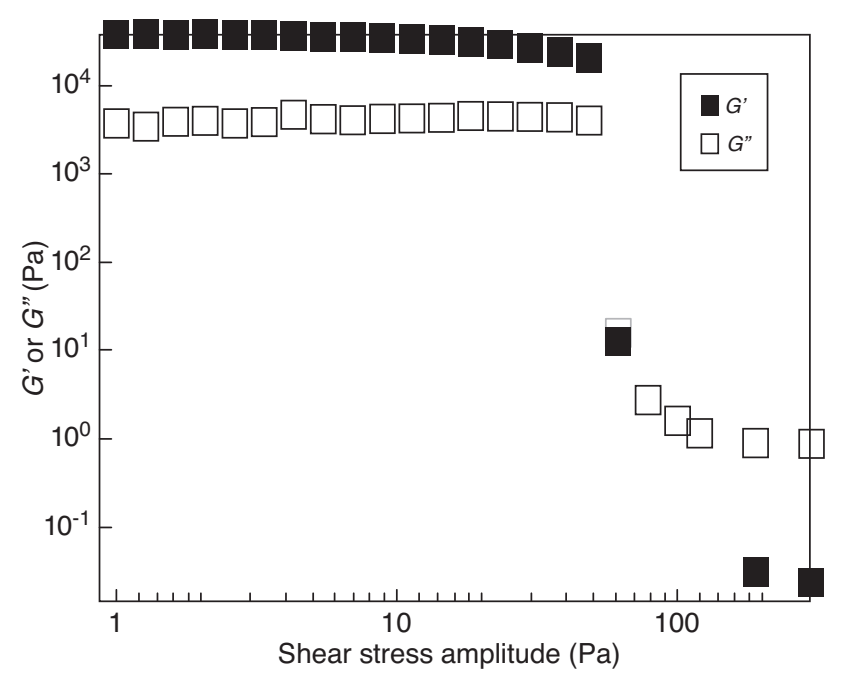

Figure 2

Variations of storage $G^{\prime}$ (filled square) and viscous $G$ " (empty square) modulus in function of the shear stress. Oscillatory shear experiment at a frequency of $1 \mathrm{~Hz}$ for a cement suspension of solid volume fraction 0.44 . The experiment has been performed with a controlled stress rheometer (shear stress amplitude sweeping). 


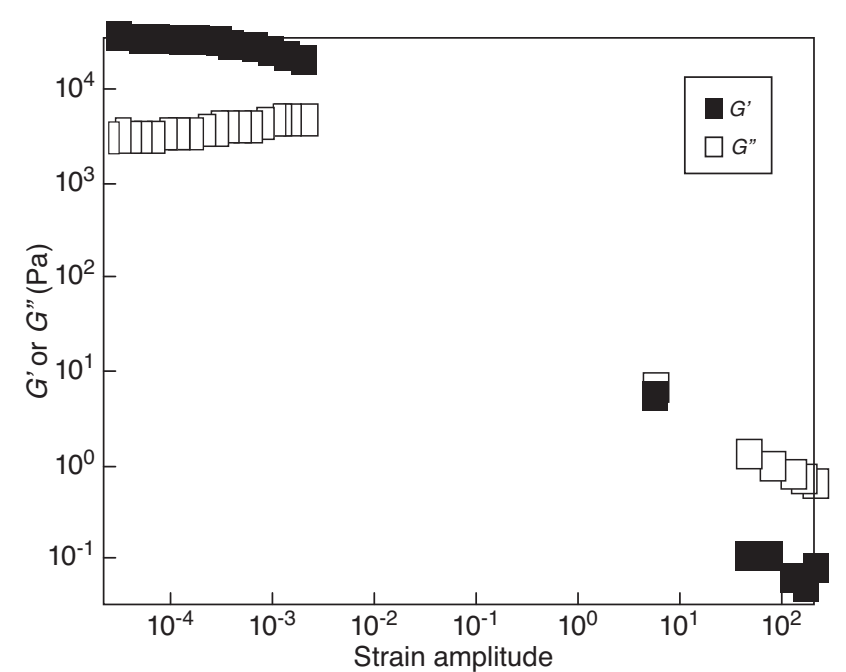

Figure 3

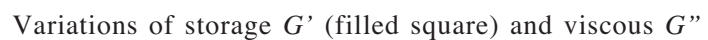
(empty square) modulus with strain amplitude. Oscillatory shear experiment at a frequency of $1 \mathrm{~Hz}$ for a cement suspension of solid volume fraction 0.44 . The experiment has been performed with a controlled stress rheometer (shear stress amplitude sweeping).

corresponding to two different states of the material, existing respectively at low and high strain or stress. Chougnet et al. [35] confirmed this interpretation by studying the variation of the degree of non-linearity, defined as the ratio of the third to the first harmonic. Chougnet et al. [35] determined the degree of non-linearity by a Fourier analysis of oscillatory data obtained using a controlled-strain rheometer. Their conclusion on this transition is in agreement with Heymann et al.'s one [36], who observed a similar transition from a first linear zone in which the suspension has a solid-like behaviour to a second linear zone in which it exhibits a liquid-like behaviour.

In order to have a better insight of the structure change of the material under stress, we performed oscillatory tests over a range of frequencies in the two linear viscoelastic regions previously evidenced. Figure 4 show that, for $\tau^{0}<\tau_{c}^{0}$, the two moduli $G$ ' and $G$ ' are independent of the frequency and $G$ ' is much higher than $G$ '; hence, it is a solid-like behaviour which corresponds to the well-known gel state of cement pastes under static conditions. In this gel state, the complex modulus $G^{*}$ gel is almost equal to the storage modulus $G_{\text {gel }}$. $G^{*}$ gel can be related to a cohesion energy per volume unit $E_{c}$, defined by the following equation:

$$
E_{c} \equiv \int_{0}^{\gamma_{c}^{0}} G_{g e l}^{*} \cdot \gamma \cdot d \gamma=\frac{1}{2} G_{g e l}^{*} \cdot\left(\gamma_{c}^{0}\right)^{2} \approx \frac{1}{2} G_{g e l}^{\prime} \cdot\left(\gamma_{c}^{0}\right)^{2}
$$

where $\gamma_{c}^{0}$ is the critical deformation amplitude.

The cohesion energy represents the energy required to break the gel structure in the cement paste at rest. $\gamma_{c}^{0}$ being independent of the solid volume fraction in the studied systems, $E_{c}$ varies like the storage modulus. When the solid fraction is increased, the storage modulus in the gel state increases.

For $\tau^{0}>\tau_{c}^{0}$, as one can see in Figure 4, a viscous region exists. In this region, the loss modulus predominates and a liquid-like behaviour prevails. The slopes of the log-log plots for $G^{\prime}(\omega)$ and $G^{\prime \prime}(\omega)$ are slightly different from the classic values of, respectively, 2 and 1 . However, the modulus of the complex viscosity is practically constant in this range of frequencies (not shown). So, the liquid state can be
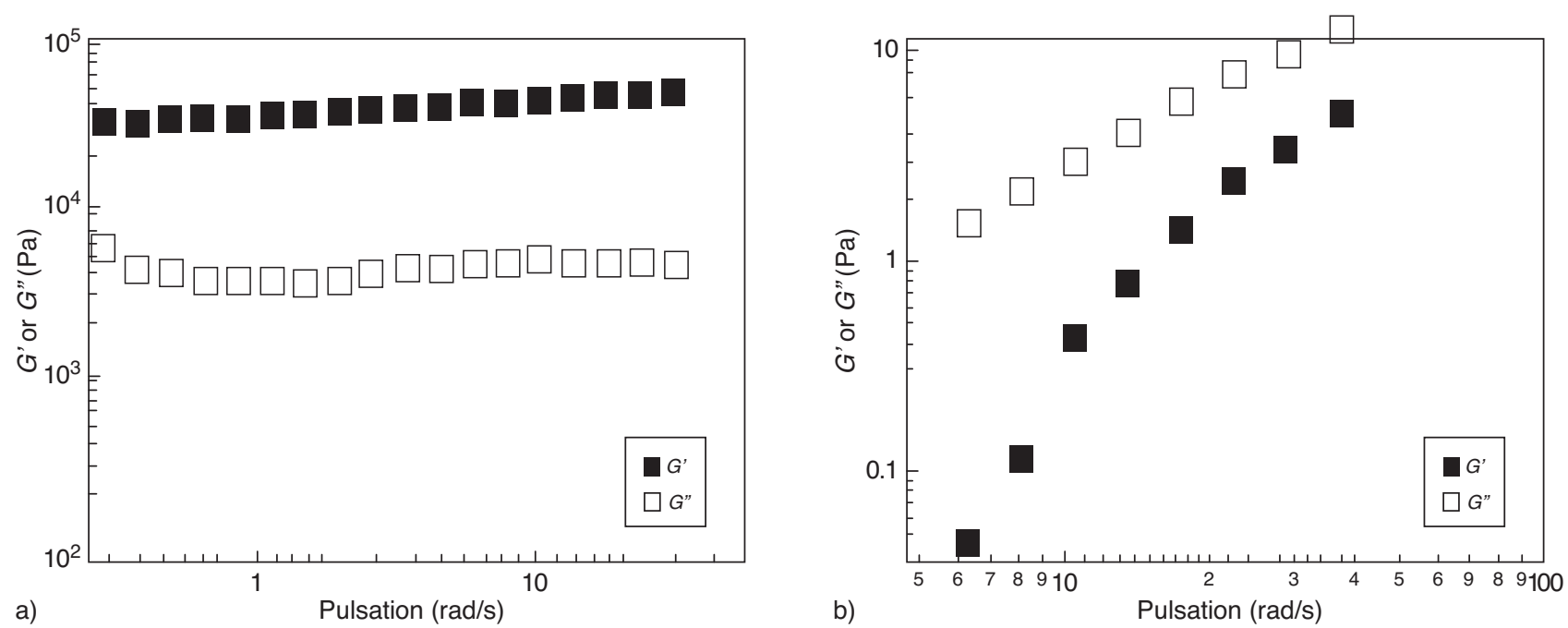

Figure 4

Variations of storage (filled square) and viscous (empty square) modulus in oscillatory shear for cement suspensions.

a) Shear stress amplitude $\tau_{0}=2 \mathrm{~Pa}$ (gel behaviour); b) Shear stress amplitude $\tau_{0}=80 \mathrm{~Pa}$ (liquid behaviour). 
characterised by the complex viscosity, $\eta^{*}$. The values the complex viscosity are given in Table 3 .

All these features show that under oscillatory shear with increasing amplitude the cement pastes present an abrupt transition from a gel state to a liquid state at a critical stress value. This behaviour in oscillatory shear can be explained by the existence of percolating aggregates within the suspension. Chougnet et al. [38] have modelled the aggregation mechanisms in cementitious suspensions and their influence on the rheological properties of such complex fluids.

\subsubsection{Polymer/Cement Composite Suspensions}

Adding polymer powder does not qualitatively modify the rheological behaviour of cement slurries. The sharp transition from a gel state to a liquid state at a critical stress is still observed (Fig. 5). In the gel state, the storage modulus measured for different cement suspensions is shown in Figure 6. At fixed $\varphi_{c w}$ parameter, when polymer is added to a cement suspension, the modulus increases due to the increase in the solid volume fraction. But, at a given total solid volume fraction, replacing cement particles by polymer ones induces a decrease of the storage modulus. We attribute this lower storage modulus to the existence of weaker attractive interactions between polymer and cement particles than the ones prevailing between cement particles.

For the composite suspensions, the polymer contribution to the cohesion energy, $E_{c}^{p o l}$, can be deduced from the

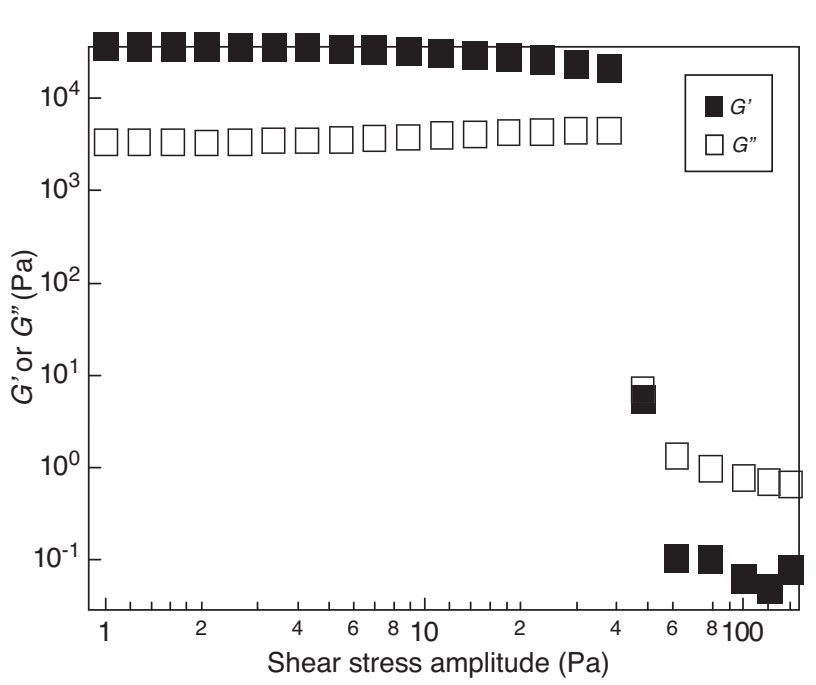

Figure 5

Variation of the storage modulus $G^{\prime}$ (filled square) and the viscous modulus $G$ " (empty square) with the shear stress amplitude for a polymer powder/cement composite. Oscillatory shear experiment at a frequency of $1 \mathrm{~Hz}$ for $\varphi_{c w}=$ 0.39 and $V_{p} / V_{c}=0.32$. The experiment has been performed with a controlled stress rheometer (shear stress amplitude sweeping).

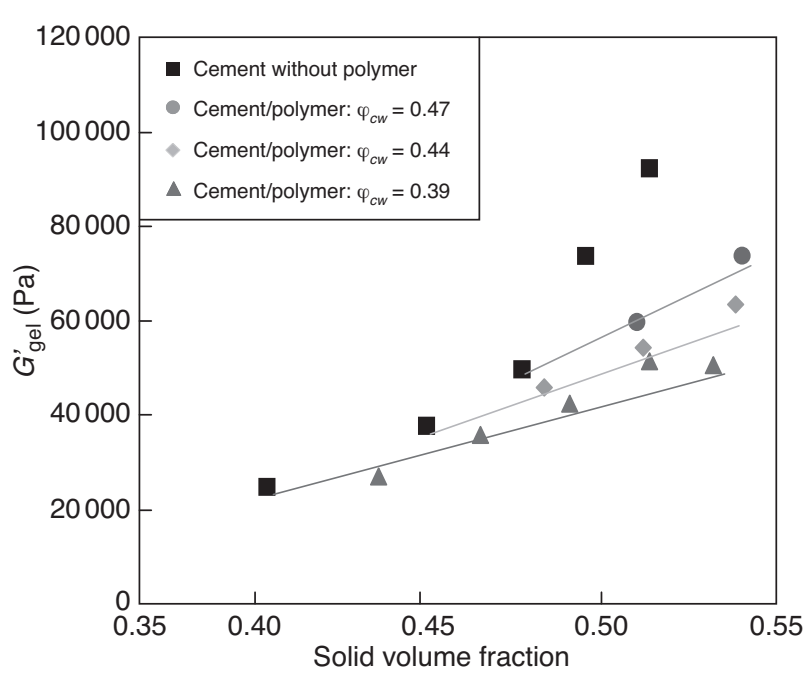

Figure 6

Variations of the storage modulus in the gel state with the solid volume fraction for cement suspensions containing or not polymer powder.

composite cohesion energy, $E_{c}$, and from the cement contribution, $E_{c}^{c e m}$ by assuming, in a first approximation, the additivity the different contributions.

$$
E_{c}=E_{c}^{c e m}+E_{c}^{p o l}
$$

We observed that the critical strain $\gamma_{c}^{0}$ remains constant when polymer is added: $\gamma_{c}^{0}=0.15 \%$ for polymer/cement suspensions. So the assumed additivity of the different contributions to the cohesion energy leads to a similar relation between the storage modulus of the composite suspension $G_{g e l}$, of the polymer $G_{g e l}^{p o l}$ and of the cement $G_{g e l}^{\text {cem }}$ contributions:

$$
G_{g e l}^{\prime}=G_{g e l}^{\prime c e m}+G_{g e l}^{p p l}
$$

In the present work, the cement contributions $E_{c}^{c e m}$ and $G_{\text {gel }}^{, c e m}$ are supposed to be similar to those of a cement suspension having the same mineral volume fraction. As it can be seen in Figure 7, the contribution of the polymer powder $G_{g e l}^{p o l}$ does not depend on the $\varphi_{c w}$ parameter of the suspension. It seems to proportionally increase with the polymer volume fraction, so the additive hypothesis seems plausible. As we observed by scanning electron microscopy that the polymer particles are well dispersed in the set cement pastes (Fig. 8), it can be thought that in the gelled suspension (prior to the setting), each polymer particle is surrounded by cement grains. Due to the fact that the polymer particles are isolated from each other (in the range of polymer volume fraction studied), polymer-polymer interactions are considered to be negligible justifying the additivity of the sole polymer and cement contributions in the cohesion energy. 


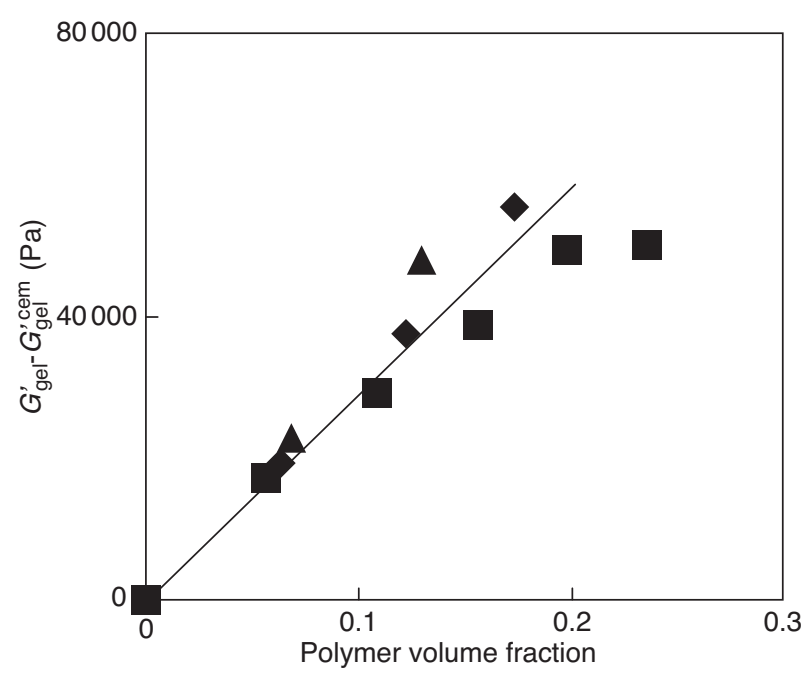

Figure 7

For cement cement/polymer composite suspensions, contribution of the polymer to the storage modulus as a function of the polymer volume fraction. Cement and polymer suspensions of $\varphi_{c w}=0.39$ : filled square, of $\varphi_{c w}=0.44$ : filled diamond, of $\varphi_{c w}=0.47$ : filled triangle.

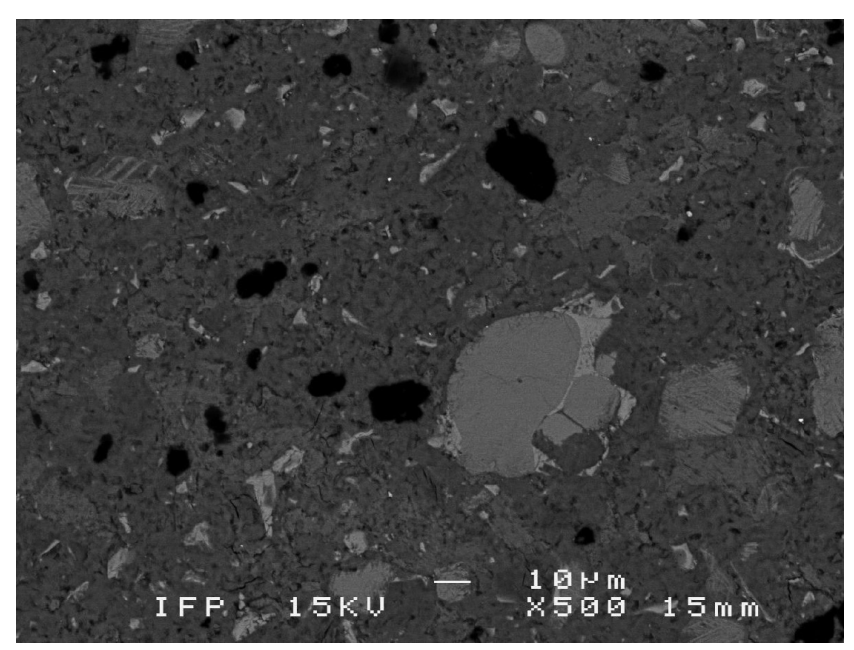

Figure 8

SEM micrograph of a set cement paste containing polymer. Observation in chemical contrast: in black, polymer particles, in dark grey hydration products and in light grey unhydrated cement particles.

Other techniques (NMR and DSC) have been used to characterise the specific interactions between cement and polymer particles. Some of the results are described in the following parts; a more comprehensive study will be published later.

\subsection{Influence of Redispersible Polymer Powder on the Cement Hydration}

\subsubsection{Calorimetry}

As soon as cement powder is in contact with water, chemical reactions occur. After a few minutes, these reactions decrease and remain very low during the so-called "dormant period". The duration of this period was measured by calorimetry for the different cement pastes. We call induction time, $t_{\text {ind }}$, the time corresponding to the end of the dormant period (Fig. 9). In order to evidence the effect of the polymer on the hydration of the cement paste, we introduce the time shift, $\delta t_{\text {ind }}$, defined by:

$$
\delta t_{\text {ind }}=\frac{t_{\text {ind }}-t_{\text {ind }}^{0}}{t_{\text {ind }}^{0}}
$$

where $t_{\text {ind }}$ is the induction time of the composite paste and $t_{\text {ind }}^{0}$ the induction time of a cement paste, measured at the same temperature and pressure. In our experiments, a nitrogen pressure of $9 \mathrm{MPa}$ has been applied to the pastes. For both atmospheric pressure and $9 \mathrm{MPa}$, it can be noticed that $t_{\text {ind }}^{0}$ does not depend on the solid volume fraction of the cement paste (Fig. 10). Figure 11 represents the variations of $\delta t_{\text {ind }}$ with the polymer volume fraction and for the different temperatures studied. The effect of polymer is very different below and above its glass transition temperature, $T_{g}$, which is about $60^{\circ} \mathrm{C}$. Below its $T_{g}$, adding polymer powder decreases the induction time of the cement paste proportionally to the polymer volume fraction. We can attribute this acceleration to the increase of alkali ions concentration induced by the polymer addition, and its ability to fix calcium ions. Indeed, these phenomena increase the dissolution ability of the

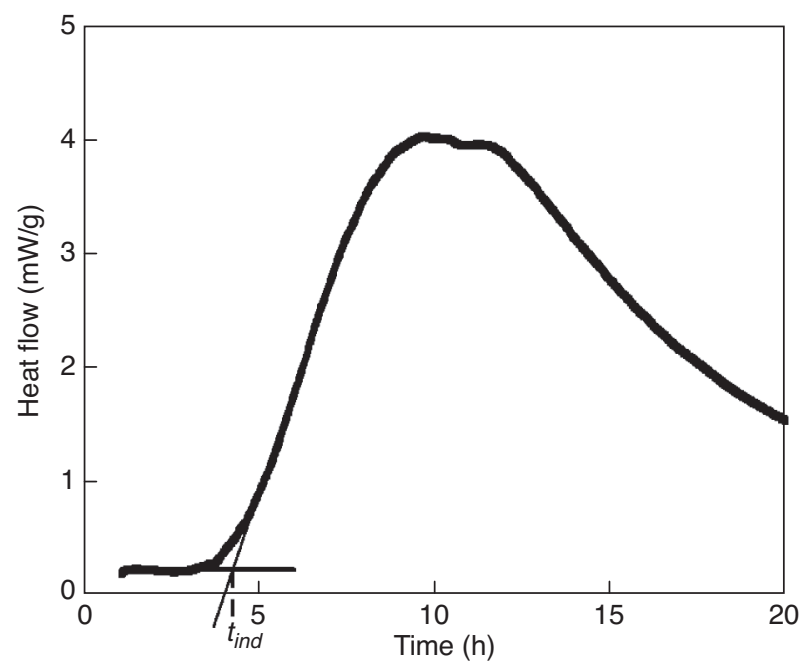

Figure 9

Heat flow in $\mathrm{mW}$ per gram of cement as a function of time for a cement slurry (Temperature: $30^{\circ} \mathrm{C}$ ). 


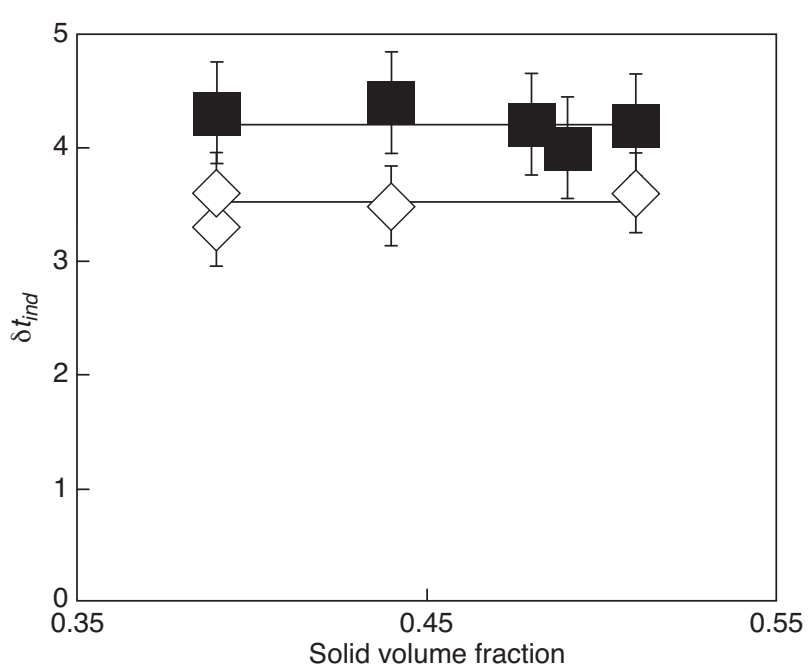

Figure 10

Variation of the induction time with the solid volume fraction for polymer-free cement suspensions at $30^{\circ} \mathrm{C}$. The experiments were carried out at atmospheric pressure (black square) and $9 \mathrm{MPa}$ (open diamond).

anhydrous particles of cement, which explains the acceleration of the hydration reactions observed when some polymer is added. The ability of the polymer to fix calcium ions is due to both the presence of adsorbed surfactants on polymer particles and of acrylate groups formed by saponification of ester acrylate at high $\mathrm{pH}$. It could explain the reason why the polymer particles develop a very good affinity for C-S-H hydrates, as can be seen by SEM (Fig. 12).

At temperatures greater than the $T_{g}$ of the polymer, adding some polymer powder increases the induction time. This retarding effect of the polymer, described in the literature [14-18, 39, 40], can be explained by the adsorption of polymer particles on cement particles. Merlin et al. [40] has shown that setting retardation is linearly related to the cement surface coverage by the latex particles. In our case, the retarding effect is enhanced at temperatures above the $T_{g}$ because the polymer is softened. The delay increases with the temperature due to the increase of the polymer softening. This phenomenon is in competition with the increase of the anhydrous particle dissolution, which explains the non-linear evolution of $\delta t_{\text {ind }}$ with the polymer volume fraction: at the smallest polymer volume fraction, the retarding effect dominates, but for polymer volume fractions above 0.15 , it is counterbalanced by the acceleration effect.

\subsubsection{Solid State NMR}

Figure 13 shows the ${ }^{29} \mathrm{Si}$ spectra obtained with cement pastes hydrated during 1 year in sealed conditions at room temperature. One of the paste does not contain any polymer,

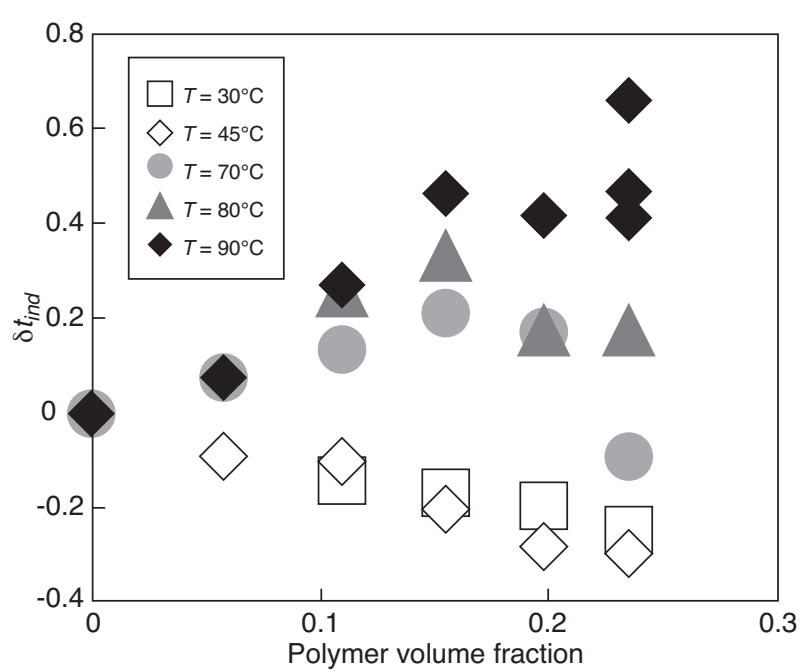

Figure 11

Variations of the induction time, $\delta t_{\text {ind }}$, with the polymer volume fraction for composite suspensions at different temperatures under a nitrogen pressure of $9 \mathrm{MPa}$.

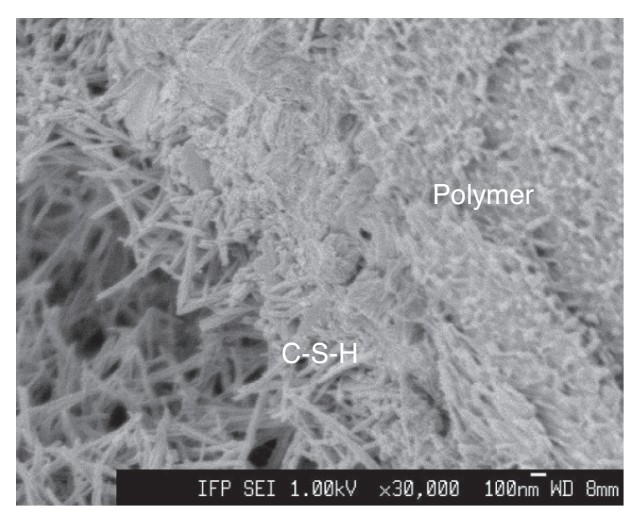

Figure 12

Fracture of a composite cement of composition $(0.39 ; 0.47)$ observed by SEM (topographic contrast).

cement volume fraction being equal at 0.39 , and the other contains the maximum possible amount of polymer powder, and has a composition of $\left(\varphi_{c w}=0.39 ; V_{p} / V_{c}=0.79\right)$. Three main peaks can be seen on these spectra: one, at $-71 \mathrm{ppm}$, corresponding to the $Q^{0}$ species, which are the silicate groups existing in anhydrous cement particles. The presence of this peak shows that even after one year of hydration, some anhydrous particles remain in the cement paste. The other peaks, at -79 and $-85 \mathrm{ppm}$, correspond to the $Q^{1}$ and $Q^{2}$ species, that are found respectively to the end and in the middle of the silicate chains of the C-S-H hydrates. The two spectra obtained for pastes with or without polymer have been normalized with respect to the $Q^{0}$ peak: so it can be seen that the hydration degree decreases when some polymer 


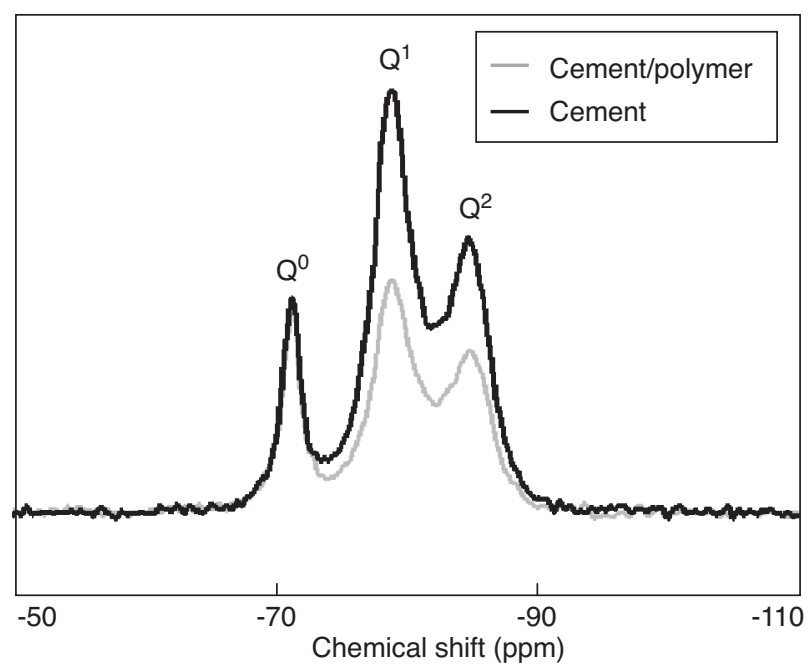

Figure 13

${ }^{29} \mathrm{Si}$ spectra of a cement paste with no polymer $(0.39 ; 0)$ and a cement paste containing polymer $(0.39 ; 0.79)$ hydrated for 1 year at room temperature.

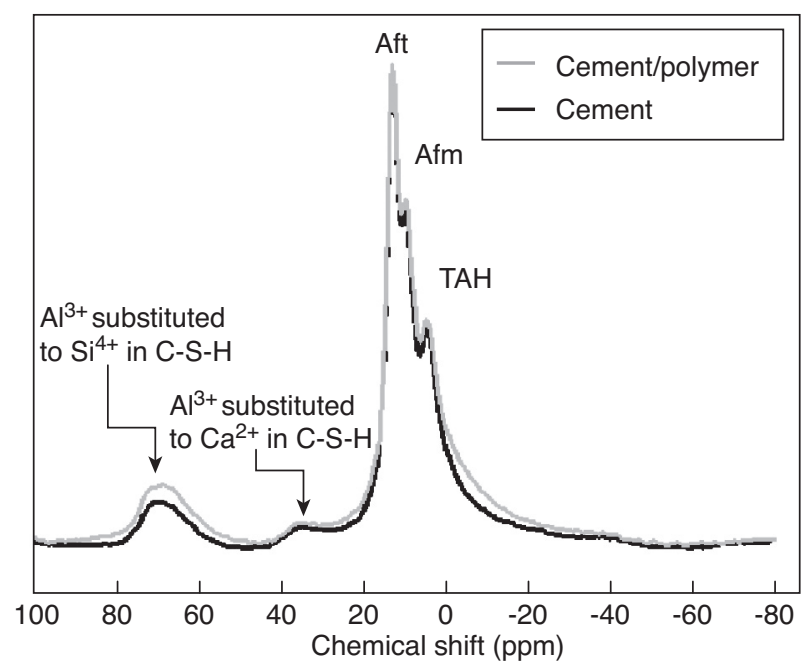

Figure 14

${ }^{27} \mathrm{Al}$ spectra of a cement paste with no polymer $(0.39 ; 0)$ and a cement paste containing polymer $(0.39 ; 0.79)$ hydrated for 1 year at room temperature. is added. This result, in agreement with the results obtained by calorimetry [33], may be explained by the decrease of capillary space available. Spectra of cement pastes containing or not some polymer powder hydrated during one month at $90^{\circ} \mathrm{C}$, with a nitrogen pressure of 90 bars, lead to the same conclusion.

Figure 14 shows the ${ }^{27} \mathrm{Al}$ spectra obtained with a cement paste without polymer powder having a solid volume fraction of 0.39, and a composite paste whose composition is the following $\left(\varphi_{c w}=0.39 ; V_{p} / V_{c}=0.79\right)$. These systems have been hydrated during one year at room temperature. The two spectra are very similar which means that after one year of hydration, the polymer has little effect on the different aluminate hydrates detected (Tab.4). On the ${ }^{27} \mathrm{Al}$ spectra, the anhydrous aluminate phases cannot be observed. The evidenced phases are in accordance with previous studies [41].

TABLE 4

Aluminate phases detected by ${ }^{27} \mathrm{Al} \mathrm{NMR}$

\begin{tabular}{c|c}
\hline Chemical shift $(\mathrm{ppm})$ & Phase \\
\hline $70 \mathrm{ppm}$ & $\mathrm{Al}^{3+}$ substituted to $\mathrm{Si}^{4+}$ in C-S-H \\
\hline $35 \mathrm{ppm}$ & $\mathrm{Al}^{3+}$ substituted to $\mathrm{Ca}^{2+}$ in C-S-H \\
\hline $13 \mathrm{ppm}$ & Ettringite Aft \\
\hline $10 \mathrm{ppm}$ & Monosulfoaluminate Afm \\
\hline $4 \mathrm{ppm}$ & Third aluminate hydrates: amorphous phase \\
\hline
\end{tabular}

The same conclusions were drawn with spectra of cement pastes hydrated one month at $90^{\circ} \mathrm{C}$.

\subsection{Study of a Low Permeability Polymer/Cement Composite}

The previous parts of this work have shown that the redispersible polymer powders could be incorporated in cement slurries without impairing their early age properties [42]. As an example of application, a low permeability polymer/cement composite has been designed in order to get cementing materials with enhanced durability. This new cementing material comprises four components with different particle size distribution. The components are fume silica, portland cement, crushed sand and polymer particles. Mixing well suited amounts of these four powders allow to optimize the packing of the cementing materials. In order to lighten the slurry, we designed a composition with a $P / C=35 \mathrm{wt} \%$. The volume fraction of the composite slurry is quite large, $63.7 \%$ (by comparison, a conventional oilwell cement slurry has a solid volume fraction of $42 \%$ ). The achieved specific gravity of the material equals to $1.66 \pm 0.01 \mathrm{~g} / \mathrm{cm}^{3}$. The water/cement ratio equals to 0.45 but the water/solid ratio is much more lower $(0.27)$. The studied low permeability slurry contains an antifoamer, a fluid loss reducer and a dispersant. To prepare the slurry, we mixed the dry powder (mineral and polymer ones) with the same apparatus used in the first part of this work. Then, the dry blend is mixed with water in a warring blender. We also prepared a conventional lightweight slurry. This slurry comprises portland cement, bentonite (weight ratio bentonite/cement equals to $2 \%$ ). The $W / C$ is fixed at 0.73 to achieve a specific gravity of 1.66 .

Cylinders and prisms made with the formulations described above were prepared and cured at a temperature of 


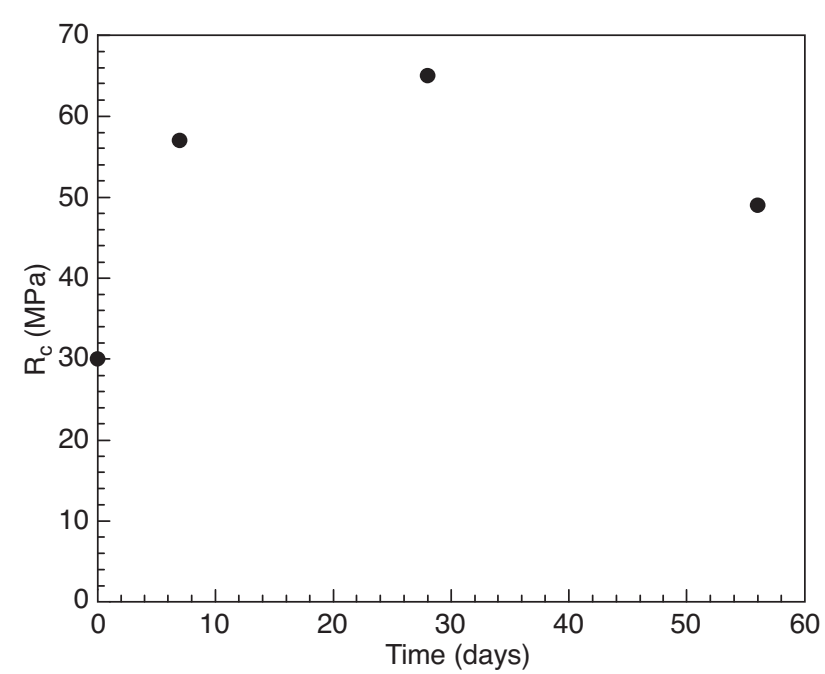

Figure 15

Compressive strength of the low permeability composite material in function of the ageing time. Ageing fluid: water, Temperature: $80^{\circ} \mathrm{C}$, Pressure: $7 \mathrm{MPa}$.

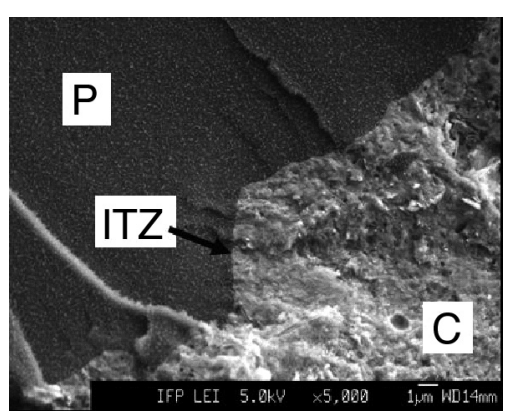

Figure 16

SEM image of the low permeability composite material showing the good bonding between polymer particles and cement matrix. P: polymer particle. C: hardened cement matrix. ITZ: Interfacial Transition Zone.

$60^{\circ} \mathrm{C}$. After one week, some of the cylinders and prisms have been used to measure mechanical properties and permeability. The remaining specimens were put in an ageing cell filled with water to study the variation of the mechanical resistance as a function of time. The ageing time were 7, 28 and 56 days. Pressure and temperature were fixed at $7 \mathrm{MPa}$ and $80^{\circ} \mathrm{C}$ respectively. We used cylinders with $25 \mathrm{~mm}$ in diameter and $50 \mathrm{~mm}$ in length. The dimensions of the prisms were $20 \times 20 \times 160 \mathrm{~mm}$. Compressive and flexural strengths measurements were performed. The water permeability of cylindrical sample was measured thanks to an Hassler-type cell. A $6 \mathrm{MPa}$ differential pressure was applied to cement cylinder with a confining pressure of $8 \mathrm{MPa}$.
Table 5 gives the results of the mechanical measurements performed on the low permeability composite materials and on the conventional lightweight one after 1 week of curing. We can observe that the low permeability composite material exhibits mechanical properties which are of the same order of a conventional slurry mixed at a specific gravity of $1.9 \mathrm{~g} / \mathrm{cm}^{3}$. Therefore, the use of the studied polymer powder allows the design of a lightweight cementing materials with optimized mechanical properties. By comparison, the same material $(W / C=0.27)$ but incorporating only mineral components has a compressive strength of about $100 \mathrm{MPa}$ and an elastic modulus of $20 \mathrm{GPa}$. The incorporation of polymer particles allows to lower the elastic modulus by almost a factor 4 .

TABLE 5

Mechanical properties of the tested lightweight cementitious materials

\begin{tabular}{c|c|c|c}
\hline Formulation & $\begin{array}{c}\text { Compressive } \\
\text { strength (MPa) }\end{array}$ & $\begin{array}{c}\text { Flexural } \\
\text { strength }(\mathrm{MPa})\end{array}$ & $\begin{array}{c}\text { Elastic modulus } \\
(\mathrm{GPa})\end{array}$ \\
\hline $\begin{array}{c}\text { Low permeability } \\
\text { composite material }\end{array}$ & 30.0 & 9.8 & 5.22 \\
\hline $\begin{array}{c}\text { Conventional } \\
\text { lightweight cement }\end{array}$ & 10 & 2.6 & 3.32 \\
\hline
\end{tabular}

The cement system lightened with water and bentonite exhibits a compressive of $10 \mathrm{MPa}$, three times lower than the value of the composite slurry, and a flexural strength of $2.6 \mathrm{MPa}$ which is 3.5 times lower than the flexural strength of the composite slurry.

Figure 15 shows the variation of the compressive strength of the low permeability composite material aged in water for different exposure periods. One can see that during the first month of ageing the mechanical resistance continues to increase. Between one and two months, the compressive strength decreases down to $50 \mathrm{MPa}$; but the 2-month value is 1.5 higher than the initial one. Therefore, during the first months, the composite cementitious system exhibits a good behaviour.

The water permeability of the composite material is $2 \times 10^{-19}$ $\mathrm{m}^{2}$ (i.e. $0.2 \times 10^{-3} \mathrm{mD}$ ). Thanks to this low permeability, one can expect improved durability of the composite material when placed in contact with aggressive fluids.

The optimized mechanical properties and the low permeability of the composite materials can be explained by a good compatibility between the polymer and the cement matrix as already stated in the first part of this work. Figure 16 shows a detail of the microstructure of the composite material. In this picture, we can observe the interface between polymer particle and the cement matrix. We notice a very good bonding between the organic material and the inorganic one. This Interfacial Transition Zone (ITZ) does not appear as a porous area compared with the bulk cement matrix as can often be seen in concrete at the interface between cement 
paste and aggregates. This is probably due to specific interactions between polymer and cement particles as mentioned above. This also explains the good mechanical properties and the very low permeability of the hardened composite material.

\section{CONCLUSION}

Both polymer-free cement slurry and polymer/cement composite slurries have been studied. In oscillatory shear, at a given frequency, two quasi-linear domains are observed for cement slurries: one at low shear stress amplitudes, in which the suspensions present an elastic solid behaviour, and one at high stress amplitudes, in which they present a liquid-type behaviour. The cementitious pastes present a sharp transition from the gel state to the liquid state at a critical stress value. This sharp transition could be due to the existence of percolating aggregates within the suspension.

Adding polymer powder does not qualitatively change the rheological behaviour of the cementitious suspensions. At a given solid volume fraction, replacing cement particles by polymer ones decreases the storage modulus in the gel state, and the viscosity in the liquid state. In the gel state, we evidenced that the polymer contribution to the cohesion energy is proportional to the amount of polymer powder. It does not depend on the solid volume fraction of the polymer-free cement suspension considered. We attribute the lower storage modulus to the existence of weak attractive interactions between polymer particles and cement grains.

At temperatures below the glass transition temperature of the polymer, $T_{g}$, adding polymer decreases the induction time. Above $T_{g}$, the adsorption of polymer on cement particles leads to an increase of the induction time. For field application, it means that polymer structureproperties relationships (composition and $T_{g}$ ) can be adapted to the required characteristics of the cement slurry for well depth and configuration (rheological behaviour and setting time).

At any temperature comprised between $20^{\circ} \mathrm{C}$ and $90^{\circ} \mathrm{C}$, the hydration degree of cement is lower when polymer is added, which was observed by calorimetry and ${ }^{29} \mathrm{Si} \mathrm{NMR}$. ${ }^{27} \mathrm{Al}$ NMR shows that at long periods of hydration, the aluminate hydrates formed are the same in presence or not of polymer.

All these results demonstrate that such redispersible polymers can be used to design new cementing materials. A low permeability composite material has been designed by using polymer powder. This composite material exhibits both enhanced mechanical characteristics and low permeability. Moreover, we evidenced an excellent bonding between polymer particles and the hardened cement matrix.

\section{ACKNOWLEDGEMENTS}

The authors sincerely thank J.B. d'Espinose (ESPCI) and D. Dalmazzone (ENSTA) for their contribution to respectively NMR and calorimetry experiments.

\section{REFERENCES}

1 Ohama Y. (1998) Polymer-based admixtures, Cement Concrete Comp. 20, 189-212.

2 Audibert A., Noik C., Rivereau A. (2005) US patent 6.656.263.

3 Riley V.R., Razl I. (1974) Polymer additives for cement composites: a review, Composites 27-33.

4 Sakai E., Sugita J. (1995) Composite mechanism of polymer modified cement, Cement Concrete Res. 25, 127-135.

5 Schulze J. (1999) Influence of water-cement ratio and cement content on the properties of polymer-modified mortars, Cement Concrete Res. 29, 909-915.

6 Schulze J., Killermann O. (1999) Long-term performance of redispersible powders in mortars, Cement Concrete Res. 31, 357362 .

7 Bureau L., Alliche A., Pilvin Ph., Pascal S. (2001) Mechanical characterization of a styrene-butadiene modified mortar, Mat. Sci. Eng. A-Struct. 308, 233-240.

8 Pascal S. (2002) Comportement mécanique de composites mortier-polymère, $P h D$ Thesis, École Centrale des Arts et Manufactures.

9 Nehdi M., Summer J. (2002) Recycling waste paint in concrete, Cement Concrete Res. 33, 857-863.

10 Zhong S., Chen Z. (2002) Properties of latex blend and its modified cement mortars, Cement Concrete Res. 32, 1515-1524.

11 Atzeni C., Massidda L., Sanna U. (1989) Rheological behaviour of cements mixed with polymeric lattices, Int. J. Cement Composites and Lightweight Concrete 11, 215-219.

12 Gregory T., O'Keefe S.J. (1990) Rheological measurements on fresh polymer-modified cement pastes, Proceedings of the International Conference organized by the British Society of Rheology, pp. 69-79.

13 Nicoleau L., Garrault S., Nonat A., Pourchet S. (2003) Étude par rhéométrie dynamique des interactions physico-chimiques entre les latex et les phases minérales constituant le ciment, Congrès $d u$ GFR, Brest, 2003.

14 Beeldens A., Van Gemert D., Ohama Y. (2003) Integrated model of structure formation in polymer modified concrete, Proceedings of the 11th International Congress on the Chemistry of Cement.

15 Ollitrault-Fichet R., Gauthier C., Clamen G., Boch P. (1998) Microstructural aspects in a polymer-modified cement, Cement Concrete Res. 28, 1687-1693.

16 Zeng S., Short N.R., Page C.L. (1996) Early-age hydration kinetics of polymer-modified cement, Adv. Cem. Res. 29, 1-9.

17 Janotka I., Madejova J., Stevula L., Frt'alova D.M. (1996) Behaviour $\mathrm{Ca}(\mathrm{OH})_{2}$ in the presence of the set styrene-acrylate dispersion, Cement Concrete Res. 26, 1727-1735.

18 Rottstegge J., Arnold M., Herschke L., Glasser G., Wilhelm M., Spiess H.W., Hergeth W.D. (2005) Solid state NMR and LVSEM studies on the hardening of latex modified tile mortar systems, Cement Concrete Res. 35, 2233-2243.

19 Nelson E.B. (ed.) (1990) Well Cementing, Schlumberger Educational Services, Houston. 
20 Taylor H.F.W. (1997) Cement Chemistry, 2nd ed., Thomas Telford Publishing, London.

21 Powers T.C. (1958) Structure and Physical Properties of Hardened Portland Cement Paste, J. Am. Ceram. Soc. 41, 1-6 and references therein.

22 Nachbaur L., Mutin J.C., Nonat A., Choplin L. (2001) Dynamic mode rheology of cement and tricalcium silicate pastes from mixing to setting, Cement Concrete Res. 31, 183-192.

23 Jiang S.P., Mutin J.C., Nonat A. (1995) Studies on the Mechanism and Physico-Chemical Parameters at the Origin of Cement Setting. I. The Fundamental Processes involved during Cement Setting, Cement Concrete Res. 25, 779-789.

24 Jiang S.P., Mutin J.C., Nonat A. (1996) Studies on the Mechanism and Physico-Chemical Parameters at the Origin of Cement Setting. II. Physico-Chemical Parameters determining the Coagulation Process, Cement Concrete Res. 26, 491-500.

25 Nachbaur L., Nkinamubanzi P.C., Nonat A., Mutin J.C. (1998) Electrokinetic Properties which control the Coagulation of Silicate Cement Suspensions during Early Age Hydration, $J$. Colloid Interf. Sci. 202, 261-268.

26 Garrault-Gauffinet S., Nonat A. (1999) Experimental Investigation of Calcium Silicate Hydrate (C-S-H) Nucleation, $J$. Cryst. Growth 200, 565-574.

27 Maggion R., Bonnamy S., Levitz P., Van Damme H. (1996) A scaling model of the microstructural evolution in $\mathrm{C}_{3} \mathrm{~S} / \mathrm{C}-\mathrm{S}-\mathrm{H}$ pastes, in The Modeling of Microstructure and its Potential for Studying Transport Properties and Durability, Jennings H., Kropp J., Scrivener K. (eds), NATO ASI Series E: Applied Sciences, 304, Kluwer Academic Publishers, Dordrecht, pp. 137-155.

28 Levitz P. (2007) Toobox for 3D imaging and modeling of porous media: Relationship with transport properties, Cement Concrete Res. 37, 351-359.

29 Maggion R., Tinet D., Levitz P., Van Damme H. (1992) Microtextural evolution of CSH pastes during hydration, in Hydration and Settings of Cement, Nonat A., Mutin J.C. (eds), RILEM Proceedings 16, E\&FN SPON.

30 Shaughnessy R., Clark PE (1988) The rheological behavior of fresh cement pastes, Cement Concrete Res. 18, 327-341.
31 Lootens D. (2004) Ciment et suspensions concentrées modèles. Écoulement, encombrement et floculation, PhD Thesis, Université Paris 6.

32 Schultz M.A., Struble L.J. (1993) Use of oscillatory shear to study flow behaviour of fresh cement paste, Cement Concrete Res. 23, 273-282.

33 Chougnet A. (2006) Composites ciment/polymère : rhéologie, hydratation, PhD Thesis, Université de Bretagne Occidentale.

34 Barnes H.A., Nguyen Q.D. (2001) Rotating vane rheometry - a review, J. Non-Newton Fluid $98,1-14$.

35 Chougnet A., Audibert A., Moan M. (2007) Linear and nonlinear rheological behaviour of cement and silica suspensions. Effect of polymer addition, Rheol. Acta 46, 793-802.

36 Heymann L., Peukert S., Aksel N. (2002) Investigation of the solid-liquid transition of highly concentrated suspensions in oscillatory amplitude sweeps, J. Rheol.46,93-112.

37 Jönsson B., Wennerström H., Nonat A., Cabane B. (2004) Onset of cohesion in cement pastes, Langmuir 20, 6702-6709.

38 Chougnet A., Palermo T., Audibert A., Moan M. (2008) Rheological behaviour of cement and silica suspensions: Particle aggregation modelling, Cement Concrete Res. 38, 1297-1301.

39 Nicoleau L. (2004) Interactions physico-chimiques entre le latex et les phases minérales constituant le ciment au cours de son hydratation, $P h D$ Thesis, Université de Bourgogne.

40 Merlin F., Guitouni H., Mouhoubi H., Mariot S., Vallée F., Van Damme H. (2005) Adsorption and heterocoagulation of nonionic surfactants and latex particles on cement hydrates, J. Colloid Interf. Sci. 281, 1-10.

41 Le Saoût G., Lécolier E., Rivereau A., Zanni H. (2004) Study of oilwell cements by solid-state NMR, C.R. Chimie 7, 383-388.

42 Chougnet A., Audibert A., Moan M., Lécolier E., Mazard C., Guichard B., Valenti A. (2006) Polymer powder/cement Composites for oil and gas wells, SPE paper 102173, SPE ATCE San Antonio, TX.

Final manuscript received in July 2009 Published online in October 2009

Copyright (C) 2009 Institut français du pétrole

Permission to make digital or hard copies of part or all of this work for personal or classroom use is granted without fee provided that copies are not made or distributed for profit or commercial advantage and that copies bear this notice and the full citation on the first page. Copyrights for components of this work owned by others than IFP must be honored. Abstracting with credit is permitted. To copy otherwise, to republish, to post on servers, or to redistribute to lists, requires prior specific permission and/or a fee: Request permission from Documentation, Institut français du pétrole, fax. +33147527078 , or revueogst@ifp.fr. 